\title{
«Los naturales son ciudadanos de la gran familia boliviana». La participación indígena en la construcción del departamento del Beni, siglo XIX ${ }^{1 /}$
}

\author{
«The natives are citizens of the great Bolivian family». \\ Indigenous participation in the construction \\ of the Department of Beni, XIXth century
}

Anna Guiteras Mombiola

Universitat de Barcelona/TEIAA

En 1842, la creación del departamento del Beni implicó la extensión de la ciudadanía a sus habitantes, en su gran mayoría indígenas. A través de la legislación sancionada a lo largo del sigo XIX, se analizan las estrategias, actividades e instituciones de esta población en relación al ejercicio de las garantías constitucionales en el ámbito sociopolítico - gobierno local - y en el socioeconómico — propiedad de la tierra.

PALABRAS Clave: Ciudadanía; Legislación; Indígenas; Amazonía; Bolivia; siglo XIX.

In 1842, following the creation of the department of Beni, its native inhabitants obtained the citizenship. Through legislation enacted during the XIXth Century, this paper aims to examine the strategies, activities and institutions of this population in relation to the exercise of constitutional rights in the access in the local government and the property of the land.

Keywords: Citizenship; Legislation; Native inhabitants; Amazonia; Bolivia; XIXth century.

1 Este artículo desarrolla algunas de las tesis defendidas en mi Tesis Doctoral (Guiteras Mombiola, 2011a) y se inscribe en el proyecto HAR2009-07094, que se desarrolla en el TEIAA (2009SGR1400). Agradezco a Pilar García Jordán los comentarios y apreciaciones a versiones anteriores de este texto. 
A lo largo del siglo XIX, la mayor parte de la Amazonía boliviana estuvo bajo la jurisdicción del departamento del Beni, el más extenso y menos poblado de todo el país, siendo su población mayoritariamente indígena. Una parte de ella estaba constituida por distintas filiaciones étnicas no sometidas, dispersas en los bosques; otra parte estaba conformada por diversos grupos etnolingüísticos que habían sido reducidos en la, por entonces, provincia de Mojos. Fue en este último grupo en el que, en 1842, se fijó el Ejecutivo boliviano, interesado en adecuar el modelo misional a la normativa constitucional para equiparar a estos pueblos al resto de habitantes de la República. Como a causa de la excepcionalidad anterior las garantías dictadas «a favor de los bolivianos» no incluían a los habitantes mojeños, el estatus de la región y de sus pobladores fue modificado. En conformidad con los planteamientos modernizadores de la época y debido al interés económico del área, ${ }^{2}$ se creó el departamento del Beni y se extendió la ciudadanía a sus miembros. Ello significaba que los nativos benianos obtenían un acceso al comercio y a la propiedad, sujeto al principio de libertad auspiciado por la constitución y regido por las leyes orgánicas del país, las únicas aplicables a la población a partir de entonces. Para unos autores, el nuevo estatus jurídico no tuvo ningún resultado práctico para los pobladores; ${ }^{3}$ para otros, los nuevos derechos adquiridos solo propiciaron la expropiación de las tierras indígenas. ${ }^{4} \mathrm{Si}$ bien podemos coincidir con estos últimos para el periodo que se inicia con los albores del siglo XX, no estamos de acuerdo con hacer extensiva esa afirmación para la segunda mitad del siglo XIX. Las disposiciones legislativas sancionadas en 1842 tuvieron gran importancia para la población nativa porque su conocimiento y utilización favorecieron la actuación de una parte relevante de la misma en la definición y estructuración de la sociedad beniana. Por ello, es nuestra intención defender en este texto que las leyes gubernamentales fueron interpretadas y adaptadas por los indígenas a favor de sus intereses y en defensa de las calidades legales adquiridas. Esta afirmación implica entender la legislación no como una representación ideológica superficial y arbitraria, sino «como expresión de las fuerzas sociales, culturales y políticas». 5

2 Gamarra, 2010, 17.

3 Groff Greever, 1987; Gamarra, 2010.

4 Block, 1997, 214-215; Lehm, 1987 y 1999, 39-40.

5 Con ello rescatamos lo señalado — siguiendo a Bourdieu, 1982 - por Barragán $(1999,13)$ respecto a que la legislación «reorganizó y estructuró la sociedad sentando las bases y reglas del juego del siglo XIX. Las leyes y códigos que establecieron, asignaron e impusieron categorías y derechos sociales pueden ser descritos, entonces, como ritos de institución y ritos de legitimación». 
Su incidencia bidireccional en la sociedad no solo posibilitó un escenario que permitió la participación activa de los pueblos nativos en la construcción del departamento, sino que facilitó un paulatino proceso de institucionalización estatal en la región amazónica. ${ }^{6}$

A partir de fuentes legislativas y de una variada documentación hallada en repositorios bolivianos, relativa a la correspondencia procedente de la prefectura beniana, el concejo municipal y el ministerio del Interior, ${ }^{7}$ nos proponemos abordar los avances y retrocesos experimentados por los nativos en el ejercicio de las potestades legales adquiridas a partir de 1842. Mediante el estudio del papel de los nativos en las principales instituciones sociopolíticas benianas y de las prácticas desarrolladas por ellos para acceder a títulos de propiedad de la tierra, expondremos cómo y bajo qué parámetros parte de la población indígena beniana se vinculó a la nueva sociedad departamental. Por ello abordaremos, en primer lugar, la legislación emitida a favor de ésta, ejemplificándose su aplicación; en segundo lugar, su participación en las entidades sociopolíticas del departamento; y, en tercer lugar, el proceso y los procedimientos en el acceso a la propiedad de la tierra. Con este texto, que resalta el valor instrumental de los decretos y las instrucciones de 1842 , y posteriores, en las prácticas y estrategias de los nativos del Beni para salvaguardar sus posesiones e instituciones, nos sumamos a las investigaciones que inciden en subrayar el activo papel desempeñado por la población indígena en la construcción de las repúblicas latinoamericanas. ${ }^{8}$

6 En los últimos años se ha desarrollado un debate historiográfico que cuestiona el antagonismo entre sociedad y Estado y asume la institucionalización del mismo como producto de la interacción entre los códigos y las normas vigentes y la actividad y los movimientos sociales que se apoyan en dichas medidas por medio de continuos procesos de negociación, disputa y acuerdo. En ese contexto, las leyes son leídas, no como elementos de imposición, sino como herramientas capaces de incorporar significaciones diversas que garantizan la convivencia social y que, en su aplicación, permiten su adaptación a coyunturas sociopolíticas distintas por parte de la sociedad que, así, interviene en la conformación de la estatalidad. La propuesta epistemológica sobre el proceso de institucionalización del Estado a través de la ley ha sido tomada de Irurozqui y Galante (eds.), 2011, 7-24; Galante, Irurozqui, Argeri, 2011, 9-27.

7 Esta documentación se halla en el Archivo y Biblioteca Nacionales de Bolivia (ABNB), en el Archivo Histórico de La Paz (ALP), en el Museo de Historia de Santa Cruz (MHSC) y en el Archivo de la Casa de la Cultura del Beni (ACCB).

8 Ejemplos de este planteamiento son: Alda Mejías, 1999; Irurozqui, 2000; Escobar, 2007; Méndez, 2005; Rodríguez, 2005; Echeverri, 2009; Quijada, 2006; Quijada (ed.), 2011. 


\section{Los decretos e instrucciones de 1842, bases de conformación del departamento del Beni}

El departamento del Beni estaba habitado, en su práctica totalidad, por indígenas. La gran mayoría de estas poblaciones habían pasado por un régimen misional y, por ello, eran consideradas civilizadas. Señala David Block que durante su reducción tuvo lugar una amalgamación y reelaboración de los sistemas de organización nativos, mezclándose con los europeos. Surgiría así la cultura reduccional caracterizada por el ordenamiento urbano, la ganadería, el culto y praxis católica, el gobierno local, la organización social jerárquica y el mantenimiento de la lengua nativa; siendo posible esta cultura gracias al papel dinamizador jugado por los misioneros y la población indígena. ${ }^{9}$ Con la expulsión de los jesuitas, los nativos quedaron bajo una administración dual — civil y religiosa - cruceña. Las jurisdicciones y responsabilidades superpuestas y el desarrollo de una economía de mercado en la región obligarían, tras el proceso independentista, al replanteamiento del organigrama político-administrativo de la provincia y de la situación de sus habitantes. Sin embargo, pese al interés teórico de algunos gobernantes por incorporar la Amazonía a la vida republicana, ${ }^{10}$ nada se concretó al respecto hasta la presidencia de José Ballivián (18411847). Por el Decreto de 6 de agosto de 1842 se promulgó la independencia de la provincia de Mojos del departamento de Santa Cruz, siendo creado el departamento del Beni en noviembre de ese mismo año. ${ }^{11}$ Además, al constatarse el estado en el que se encontraban los nativos, «contrario a la naturaleza, la ilustración [y] a los principios constitucionales proclamados por la república», se estableció que:

los habitantes de Mojos y los demás pueblos comprendidos dentro de los antiguos límites de la provincia se elevan a la clase de ciudadanos bolivianos y como tales capaces de los derechos de igualdad, libertad y propiedad, que las leyes garantizan a los bolivianos (art. 2). ${ }^{12}$

9 Block, 1997. Esta tesis ha sido aceptada por la gran mayoría de investigadores de la época colonial y republicana de la región.

10 Ver MHSC, Provincias, Municipios y Cantones-serie Mojos (PMC-MJ), 1/25-21, 8 de noviembre de 1833 (copia fechada a 11 de agosto de 1839); 0/07-29, 1 de octubre de 1840.

11 Decretos de 6 de agosto de 1842 y de 18 de noviembre de 1842 en Limpias Saucedo, 2005 [1942], 3-4 y 13-14.

12 Decreto de 6 de agosto de 1842 en Ibidem, 4; el original se encuentra en ALP, Sociedad Geográfica de La Paz (SGL), 1842, 3/30. 
En consecuencia, los nativos fueron declarados propietarios de sus casas y se repartieron habitaciones en los pueblos y terrenos aptos para el cultivo y el pastoreo, entre aquéllos que quisieran adquirirlos. Se eximió a las mujeres del pago de cargas públicas, aunque ello se mantuvo para los varones, estipulándose que quedarían sujetos al pago de una contribución anual de dos pesos los que recibieran terrenos y de un peso los que no tuvieran tal asignación. Este pago sería satisfecho por indígenas y no-indígenas, pues el decreto también fomentaba la llegada de población criollomestiza a la que también se le podría aplicar el repartimiento de tierras.

Con el objetivo de evitar que esta medida quedara sin efecto se reglamentó la nueva administración política, económica y social del Beni mediante las instrucciones del 8 de agosto y del 21 de septiembre de 1842 . La primera estableció en Mojos «el régimen legal del resto de la República haciendo observar la constitución y leyes orgánicas en cuanto sea susceptible por el actual estado de los naturales a los que es necesario poner o elevar al estado de civilización, de propiedad y cultura en que se hallan los demás ciudadanos bolivianos (art. $2^{\circ}$ )». ${ }^{13}$ Con ella se fijó el organigrama de autoridades; de manera que la administración del distrito dependía de un gobernador, luego prefecto, cuyo representante en cada población sería el corregidor, con potestad sobre el resto de autoridades nativas. El corregidor era el sustituto del administrador de temporalidades que hasta entonces había asumido todos los poderes públicos y debía encargarse de recaudar las contribuciones de las que hablaba el artículo del Decreto del 6 de agosto. El ramo de justicia, a nivel departamental, dependía de un juez de letras nombrado por el gobierno y que administraba la justicia criminal o civil. Subordinados a él quedaban los jueces de paz, cuya actuación se circunscribía al ámbito local; su creación obedecía al interés por evitar que una sola persona detentara todos los poderes públicos y, así, impedir los abusos cometidos por los antiguos administradores. De ahí que se prohibiera la pena de azotes a las mujeres y se aceptaran en varones sólo por delitos de robo y embriaguez, estipulándose que únicamente deberían aplicarse por disposición judicial, quedando los corregidores, caciques e intendentes inhabilitados para practicarlos excepto en determinados casos. ${ }^{14}$

Los nuevos cargos fueron ocupados, desde el principio, por población criollo-mestiza por lo que es posible afirmar que la Instrucción

13 ALP, SGL, 1842, 3/31, Instrucción de 8 de agosto de 1842.

14 Idem. 
del 8 de agosto de 1842, como ya lo hiciera el Decreto del 6 de agosto, contenía la voluntad gubernamental de atraer población no-indígena a la región. Las autoridades debían «proteger la emigración» proporcionando viviendas y fomentando las actividades agropecuarias. ${ }^{15}$ Todo ello requirió de una evaluación de los recursos económicos existentes que permitió, a través de la segunda instrucción, dictada el 21 de septiembre de 1842, la distribución de terrenos. Se estipuló que cada familia -indígena y criollomestiza - podría acceder a la propiedad de un terreno de cultivo, uno de pastoreo y un lote urbano. Se mantuvo la propiedad estatal y eclesiástica de algunos cultivos (algodón, cacaotales), cuyo cuidado quedaría a cargo de los nativos sin tierra y a medio jornal a cargo de aquellos que poseyesen algún tipo de predio. Por último, se desposeyó a los gremios de sus estancias, estableciéndose su distribución individual a los que lo solicitaran. ${ }^{16}$

Se trató, en definitiva, de medidas que sentaron las bases del desarrollo y la conformación del nuevo departamento, y que, además, con su insistencia en el tema del reparto de terrenos y la consiguiente generación de trabajo y renta, extendieron el ejercicio ciudadano a sus habitantes. Recuérdese que desde la Constitución de 1839 se estableció una ciudadanía de naturaleza censitaria ${ }^{17}$, por la que solo podrían ser considerados parte de la misma todos los varones, mayores de edad o casados, que supieran leer y escribir, que pagasen impuestos y que tuvieran una renta mínima —que a lo largo del tiempo variaría de los 600 a los 200 pesos- proveniente de propiedades o del trabajo no ejercido en calidad de domésticos. ${ }^{18}$ Respecto al primer requisito, dada la naturaleza local del reconocimiento ciudadano y el generalizado analfabetismo que afectaba a la población indígena y no indígena, en el Beni se reconocieron como letrados a aquellos que hubieran pasado por un régimen misional y que, por lo tanto,

15 Ver artículos $4 .^{\circ}, 5 .^{\circ}, 7 .^{\circ}$ y $13 .^{\circ}$ en Idem.

16 ALP, SGL, 1842, 3/33, Instrucción de 21 de septiembre de 1842. De hecho, el Estado se erigió en único y legítimo propietario del territorio nacional y de los recursos pecuarios del Beni, aunque no se dieron disposiciones legales específicas para ello. Ver Block, 1997, 220; Roca, 2001, 440.

17 Si el sufragio censitario o capacitado, vigente en Bolivia hasta 1952, abogó por el ciudadano letrado — con independencia de juicio, voluntad y decisión—, la vecindad como principio constituyente de la ciudadanía favoreció una definición local de la misma estructurada por las nociones de cooperación y servicio a la patria. La ciudadanía fue entendida como una facultad que debía aprenderse y un privilegio a ser ganado a partir del ejercicio de acciones a favor del bien común, reconocidas positiva y públicamente por la comunidad, entre las que figuraba el trabajo, la contribución fiscal y la acción armada de los civiles en defensa de la constitución. Sobre el alcance social del sufragio censitario véase Irurozqui, 2008, 57-92; y sobre la relación vecindad-ciudadanía que se expresaba en el ámbito local véase Irurozqui, 2005b, 451-485.

18 Constitución de 1839 , arts. 8 y 12 . 
habían sido «civilizados» o capacitados para «entender» la ley. En 1830, Alcides d'Orbigny había consignado un total de 23.313 indígenas, número que se mantendría hasta la década de 1870, cuando dicho monto empezó a descender, reduciéndose a 13.624 los indígenas censados en el año $1900 .{ }^{19}$ Respecto a ellos, la población criollo-mestiza era mucho más reducida. Los 57 individuos varones contabilizados por d'Orbigny en 1830 pasaron a ser 271 habitantes a mediados de la década de 1840, poco más de 1.000 en 1855 y 9.332 individuos (varones y mujeres) en $1900 .{ }^{20}$ Dada la preeminencia indígena en la región que muestran estas cifras, con el Decreto del 6 de agosto no solo se pretendía homogeneizar ${ }^{21}$ la realidad poblacional amazónica con el resto del país, sino que la equiparación fiscal de los indígenas benianos con la población criollo-mestiza, ejemplificada en el pago de la contribución sobre la tierra que deberían efectuar los «naturales y forasteros» de la región, redundaba en un esfuerzo de uniformización ciudadana. Éste quedaba reafirmado con el nuevo estatus jurídico de los nativos que generaría un nuevo marco de relaciones entre éstos y los criollos-mestizos y daría lugar a una «nueva» sociedad amazónica organizada alrededor de la ocupación, control y explotación de la tierra y al acceso a distintas instituciones sociopolíticas locales y regionales.

La aplicación de las disposiciones mencionadas implicaba cambios en las relaciones de sus pobladores, criollo-mestizos e indígenas, al pasar, estos últimos, de ser sujetos tutelados a ser sujetos de pleno derecho. Sin embargo, hay que señalar que el artículo 2. ${ }^{\circ}$ del Decreto de 6 de agosto había hecho mayor insistencia en los derechos civiles - libertad de comercio y de propiedad - que en los políticos; ya que, como se ha indicado, la ciudadanía basada en criterios censitarios implicaba un determinado disfrute de los primeros para el ejercicio de los segundos. Si bien ello no cuestionaba el acceso de los nativos a la ciudadanía debido a que la nueva legislación no establecía diferencias de naturaleza étnica entre los bolivianos, las prácticas sociales no dejaban de ser diferenciadoras por ello. ${ }^{22}$ De ahí que, pese a que «misional» equivaliera a «civilizado», persistiese una percepción que en 1840 ya había sido verbalizada por un gobernador respecto a

19 Orbigny, 1846, 296-297; 1945 [1826-1833], 1307, 1309, 1316, 1321, 1341, 1343, 1348, 1355, 1446; ALP, SGL, 3/34, 3/37, 3/38, 3/40, 3/41, 3/42, 3/45; ABNB, Tribunal Nacional de CuentasRevisitas (TNC-Rv), Beni, 1849, 1854, 1857, 1859, 1862, 1867, 1872-74 y Oficina..., 1904, 21, 32.

20 ALP, SGL, 1844, 3/40, 3/41; Aguirre, 1855, s/p; Oficina..., 1904, 21, 32; Block, 1997, 216.

21 Sobre el principio de homogeneidad y sus complejidades, véase Quijada, 2000.

22 Barragán, 1999; Irurozqui, 2000, 56-80. 
que los «naturales indígenas [...] no están en estado de civilización ni pueden gozar de los derechos de ciudadanos». ${ }^{23}$ En cualquier caso, la voluntad homogeneizadora del proyecto de Ballivián respecto a la incorporación de los indígenas amazónicos a la sociedad republicana, fue objeto de un complejo proceso en el que fueron constantes los avances y retrocesos de los nativos benianos en el ejercicio de sus potestades constitucionales.

El principal escollo a superar fue la pervivencia de ciertas prácticas de tutelaje de origen colonial ejercidas por las autoridades públicas y algunos comerciantes siendo las más extendidas la prestación de servicios gratuitos al Estado, tales como el transporte - fluvial y terrestre- de mercancías y correos, el cultivo de las huertas, entrega de la producción o la elaboración de tejidos. ${ }^{24} \mathrm{~A}$ ello se agregó que la nueva situación jurídica de la población nativa permitió que esta participara activamente en la economía regional, pudiendo ser contratada como mano de obra por particulares para servicios domésticos, actividades productivas y el tráfico fluvial. ${ }^{25} \mathrm{La}$ coexistencia de dos formas de uso de la mano de obra, gratuita si era por mandato estatal y con compensación económica si el beneficiario era un particular, dio lugar a una connivencia de intereses públicos y privados que ignoró los derechos constitucionales de los indígenas benianos. Para revertir esta realidad, a lo largo de las siguientes décadas se aprobaron distintas normas que reiteraron tanto el reconocimiento ciudadano de los indígenas, como su integración a la modernidad en boga, si bien esto último no siempre ni necesariamente propició lo primero. ${ }^{26}$ Pese a ello, este tipo de servicios se reimplantaron y modificaron un sinfín de veces, basándose para ello en la supuesta incapacidad de los nativos para ejercer su libertad. ${ }^{27}$ También, por ejemplo, los nativos dedicados al transporte fluvial recurrieron a las leyes para defenderse, denunciaron los malos tratos, se negaron a realizar determinadas tareas y requirieron de ciertas formalidades para efectuar la navegación, ${ }^{28} \sin$ que por ello la mayoría de la población dejase

23 MHSC, PMC-MJ, 1/28-12, 12 de enero de 1840.

24 MHSC, PMC-MJ, 1/25-03, 4 de septiembre de 1839; Fondo Melgar Montaño (F/MM), C13-L2/5-0, 8 de mayo de 1840; ABNB, Ministerio del Interior (MI), Prefectura del Beni, 83/33, 28 de enero de $1843 ; 101 / 23,3$ de noviembre de 1844 y 6 de agosto de 1844 . Ver también d'Orbigny, 1945 [1835-1847], 1311-1312, 1317, 1446-1449; Block, 1997, 214, 236-237; Roca, 2001, 368.

25 Limpias Saucedo, 2005 [1942], 26-27.

26 ACCB, Circulares varias, 13 de febrero de 1843; 5 de febrero de 1846; 4 de enero de 1855 ; ABNB, MI, Prefectura del Beni, 96/48, 10 de octubre de 1843; 107/33, 30 de septiembre de 1845; 134/36, 26 de febrero de 1850; Limpias Saucedo, 2005 [1942], 117-118, 129-132, 140-41.

27 Un detalle pormenorizado de estos avances y retrocesos en Van Valen, 2011, 609-613.

28 Guiteras Mombiola, 2011b. 
de trabajar en condiciones pésimas y en lugares donde el abuso de poder era la norma. ${ }^{29}$ No sería hasta la Ley de 24 de noviembre de 1883 que fueron abolidos «todos los aranceles y tarifas impuestas por costumbre al trabajo de los naturales del Beni».30

Las dificultades y abusos sufridos por los nativos benianos han contribuido a que algunos autores concluyan que los decretos de Ballivián no tuvieron aplicación alguna, sirviendo únicamente para beneficiar a la población criollo-mestiza. ${ }^{31}$ Sin embargo, debe recordarse que la igualdad jurídica no es equivalente a equidad social, siendo la desigualdad social y la competencia desigual por los recursos compatible con el desarrollo ciudadano. Todo ello en un contexto en el que la ciudadanía basada en criterios censitarios implicaba que los derechos a disfrutarse estaban condicionados por los deberes a ejercerse; lo que suponía variadas lecturas, en ocasiones opuestas, del conocimiento, el trabajo o la tributación en la determinación de un sujeto como ciudadano. ${ }^{32}$ El peso del discurso de la capacitación, la responsabilidad y la producción también se plasmaría en el Beni con todas sus contradicciones. Así, si en la década de 1840 desde la prefectura se juzgaba necesario difundir los principios de propiedad y libertad económica entre «los más aventajados», «más laboriosos y más civilizados» para lograr el progreso de la región; posteriormente, en la década de 1860, se acordaría exonerar de los trabajos públicos a los «naturales que por su capacidad y constante inclinación al trabajo» hubieran obtenido propiedades que necesitaran cultivar, ${ }^{33}$ llegando a proponerse la permanencia de los nativos bajo un régimen de tutela, salvo de aquellos que supieran leer y escribir y reconocieran la propiedad. ${ }^{34}$ Esa narrativa sobre la limitación de la práctica ciudadana en función de sus capacidades, así como una mayor protección ante el abuso, también se reflejó en las decisiones de las autoridades locales. Ejemplo de ello fue la negativa de la prefectura en 1864 a emplear a nativos en sustitución de un piquete armado de la capital, considerado encarnación de la acción administrativa departamental y único elemento de conservación del orden y la fuerza pública en la región. Se recha-

29 Block, 1997, 218-229, 236-242; Lehm, 1999, 48-68.

30 República de Bolivia, 1884, 285-288.

31 Groff Greever, 1987; Block, 1997, 214-242; Lehm, 1999; Gamarra, 2010.

32 Irurozqui, 2000, 56-80, 327-410; 2006; 2008; Quijada, 2000, 32-55. Sobre la infracción como proceso social de adquisición de capacidades ciudadanas en Irurozqui, 2000, 179-218; 2005 a.

33 Limpias Saucedo, 2005 [1942], 43-46, 161-162.

34 Así lo expresó el religioso Cosme D. Rivero en la década de 1870, cuyo libelo se encuentra en Moreno, 1872, 281-284. 
zó hacerlo tanto por «la equivocada persuasión que existe, por desgracia, en este país de que el indio es un ser pasibo [sic] al que puede obligarse voluntariamente aunque sea a prejuicio de su interés particular», como por considerar que éste tampoco «ha de tener la representación y el prestigio que arrastra consigo el ciudadano armado». ${ }^{35}$ Es decir, al tiempo que se reconocía su peso económico en el desarrollo regional, pudiendo derivarse de él su reconocimiento ciudadano, también se le disminuía públicamente por considerársele un fácil objeto de abuso, a excepción de los más capacitados. Y fue precisamente ese discurso sobre «la capacidad» $\mathrm{y}$ «la aptitud» y de su exigencia en la adquisición de la ciudadanía lo que permitió a algunos nativos sortear los subterfugios ideológicos que les relegaban de los espacios públicos y reducían su capacidad de acción. A continuación veremos cómo el empleo de «los saberes públicos» en lo tocante al gobierno local y regional posibilitó su presencia en las entidades municipales del departamento.

\section{Los indígenas y su participación en la vida política beniana: el cabildo indígena y su papel en la construcción departamental}

La administración local del Beni requirió instituciones y autoridades políticas que gestionaran la vida pública de los pueblos, situándose a la cabeza de las mismas los sectores con mayor poder socioeconómico y político. La principal fue el concejo municipal del Beni, con sede en Trinidad, entidad autónoma de la prefectura y a la que se sujetaban distintas juntas, sólo existentes en los cantones más poblados y, por ende, que requerían de representación política a nivel municipal. Desde su instalación en $1849,{ }^{36}$ el concejo estuvo integrado por nueve miembros — siete como munícipes propietarios y tres como suplentes-que ejercían sus funciones durante dos años; estando las juntas compuestas por cinco. Los miembros de ambas entidades eran elegidos por voto directo y popular entre todos los ciudadanos con derecho al sufragio. ${ }^{37}$ De su correcto ejercicio dependía el buen desarrollo del gobierno local, por lo que sus integrantes debían residir en el lugar para evitar irregularidades en el desarrollo de las sesiones.

35 ABNB, MI, Prefectura del Beni, 183/42, 31 de diciembre de 1864 y 4 de enero de 1865.

36 Limpias Saucedo, 2005 [1942], 54.

37 Dalence, 1851, 18-19; Oficina..., 1904, XLII. 
¿Quiénes podían acceder a la municipalidad? Cuando el Ejecutivo ordenó la organización del primer concejo municipal beniano se instó al prefecto a influir en la elección de sus miembros para evitar que el cargo fuera asumido por individuos que carecieran de la necesaria preparación. ${ }^{38}$ Por entonces, la población beniana era indígena casi en su totalidad, siendo muy pocos los pobladores criollo-mestizos. Se trataba de empleados públicos, religiosos y empresarios, además de confinados políticos y condenados por delitos varios, estos últimos, «de la clase más ignorante y degradada de los pueblos de afuera» y «de influencia nociva», según las autoridades. ${ }^{39}$ Aunque es posible que en el momento de creación del departamento muy pocos individuos parecieran cumplir con los requisitos legales para actuar en la vida pública, el hecho de que el Decreto del 6 de agosto de 1842 confiriese la ciudadanía a todos los nativos «civilizados» amplió el número de participantes en el ámbito municipal. De ahí que no deba extrañar que entre las personas calificadas como ciudadanos en los registros cívicos aparecieran los nombres de diversos indígenas, quienes disfrutaron del derecho al sufragio y se postularon como electores y/o elegibles a las juntas y el concejo municipal.

Tenemos conocimiento de algunas listas de sufragantes, unas para la elección a munícipes, otras para las elecciones nacionales, de las principales poblaciones benianas. Ya en 1849, en la lista de electores para la presidencia de la República figura un número destacado de nativos en los cantones de Baures, Magdalena, San Joaquín o Santa Ana. ${ }^{40}$ Posteriormente, en 1857 y 1860, casi dos décadas después de la creación del departamento y cuando ya existía un número nada despreciable de población criollo-mestiza en la región, las listas de sufragantes revelaban un número elevado de individuos con apellidos nativos. En Trinidad, donde los no-indígenas registrados eran numerosos, la presencia nativa continuó siendo relevante, contabilizándose en 1857 dieciséis indígenas de un total de sesenta y un votantes, y habiendo en 1860 diecinueve nativos frente a los cincuenta y un criollo-mestizos anotados. Esta situación era más evidente en Loreto y Santa Ana. En 1860 la primera localidad del total de veintisiete sufragantes inscritos, ocho de ellos eran indígenas, mientras que en Santa Ana, de los dieciocho ciudadanos

38 ABNB, MI, Prefectura del Beni, 130/25, 22 de marzo de 1849.

39 Quevedo, 1861; Gibbon, 1993 [1852], 296; Block, 1997, 216; Limpias Saucedo, 2005 [1942], 36-37, 65, 96-97, 111, 128. Ver también ABNB, MI, Prefectura del Beni, 134/36, 6 de noviembre de 1850; 43/25, 12 de octubre de 1852; Jefatura Política del Beni, 171/37, 6 de febrero de 1860; ACCB, Nota contraria al envío de ladrones rateros al Beni, 31 de agosto de 1868.

40 ABNB, MI, Prefectura del Beni, 130/25, 22 de abril de 1849 y 10 de junio de 1849. 
registrados, nueve eran nativos. ${ }^{41}$ La presencia de indígenas en estas listas electorales constataba la participación de los nativos en la vida política departamental, particularmente en los asuntos de ámbito local, dependiendo su incidencia en los mismos tanto de su grado de capacitación como de la mayor o menor presencia criollo-mestiza en cada localidad. En todo caso, a día de hoy sabemos que sólo un indígena llegó a ejercer de munícipe en el concejo municipal del Beni: Frutos Nosa, corregidor y cacique de Trinidad, que ejerció de vocal a mediados de la década de $1850 .^{42}$

Pero, ¿quiénes eran los indígenas con derecho al sufragio? La sociedad nativa beniana estaba organizada en dos categorías funcionales relativas a un orden jerárquico social: el pueblo, constituido por la gente común dedicada a tareas agropecuarias, a la construcción y al transporte; y la familia, que comprendía a los neófitos hábiles en las artes y los oficios europeos, a los que ayudaban en las celebraciones litúrgicas y, sobre todo, a la elite nativa cuyos miembros eran conocidos como indios principales, indicando tal adjetivo su papel relevante en el seno de la comunidad. Éstos ocupaban los cargos más importantes del gobierno comunal y ostentaban cierto prestigio que se traducía en hablar y escribir en español. ${ }^{43}$ Sabemos que algunos de los indígenas registrados ejercían o habían ejercido de caciques $^{44}$ y otros eran propietarios de tierras cultivadas y ganados, como señalaremos más adelante, por lo que cumplían los requisitos de ser alfabetos - $\mathrm{o}$ independencia de juicio— y de tener propiedad $-\mathrm{o}$ libertad de acción - que garantizaban la emisión de un voto responsable. ${ }^{45}$ En virtud de ello, durante las primeras décadas de la historia del departamento del Beni, la elite nativa y algunos vecinos criollo-mestizos mantuvieron, a la par, el poder sociopolítico en la región. En lo concerniente a los primeros, el proceso electoral y la posibilidad de acceder a un cargo de munícipe actuaron de mecanismos para su consolidación y reconocimiento sociales entre el resto de nativos y ante la sociedad criollo-mestiza. En este sentido puede aventurarse que el nuevo estatus de ciudadano disfrutado por algunos indígenas les permitió asentar su dirigencia, reinventar jerarquías, man-

41 ACCB, Individuos con derecho a sufragio, 29 de marzo de 1857, y Sufragantes para munícipes, 16-28 de marzo de 1860.

42 ACCB, Acta de la Junta Inspectora, 7 de enero de 1856.

43 Block, 1997, 79, 144-154.

44 ABNB, MI, Prefectura del Beni, 96/48, 10 de octubre de 1843; 107/33, 30 de septiembre de 1845; 115/37, 2 de enero de 1846; 134/36, 13 de febrero de 1850; 155/38, 5 de julio de 1855; ACCB, Indagatoria, 1 de septiembre de 1866, 5 de enero de 1867; Gibbon, 1993 [1852], 303.

45 Irurozqui, 2000, 58-59, 145. 
tener el control del gobierno local y acceder a las nuevas cuotas de poder político que ofrecía el espacio nacional.

A la organización social de la población en los dos grupos ya mencionados, el pueblo y la familia, los jesuitas agregaron una entidad gestionadora del gobierno comunal: el cabildo indígena. Estaba integrado por los jefes políticos nativos, que actuaban de mediadores entre el pueblo y los religiosos, y muchos miembros de la familia. La autoridad máxima del cabildo era el corregidor, seguido del cacique y otros cargos -capitanes, intendentes, etc.- que se elegían y renovaban anualmente. ${ }^{46}$ Tras la creación del departamento del Beni, el cabildo permaneció como la institución gubernativa de los indígenas, aunque su naturaleza se vio afectada por los cambios que conllevaron las reformas territoriales y legislativas de 1842 . Como ya se ha señalado, por la Instrucción de 8 de agosto de 1842 el cargo de corregidor se incorporó al organigrama político-administrativo departamental, desgajándose esta figura de la estructura sociopolítica nativa por quedar su designación a cargo de la prefectura y ser excluida la comunidad de la decisión. El interés de la prefectura beniana por revitalizar el cabildo llevó a que a fines de la década de 1850 se aprobara un nuevo reglamento del mismo que hacía posible las pervivencias corporativas con el liberalismo. ${ }^{47}$ Por un lado, se resucitaron las parcialidades que, por entonces, estaban casi en desuso, nombrándose nuevas autoridades; $;{ }^{48} \mathrm{y}$, por otro lado, se restableció la organización del cabildo y sus funciones. ${ }^{49}$ Según se afirmaba en el considerando del reglamento el «sistema patriarcal de familias, con el nombre de parcialidad, son el faro y punto de partida para el régimen, arreglo y orden público» de la sociedad indígena; ${ }^{50}$ de ahí que se mantuviera a los indios principales y a los miembros de la familia como únicos integrantes del cabildo, distinguiéndose del resto del común por el uso de símbolos europeos ${ }^{51}$ como los trajes que vestían, el lugar principal que ocupaban en la iglesia, el hablar y escribir en español, el acceso a la propiedad de la tierra y la posibilidad de ejercer el sufragio. El cacique

46 Block, 1997, 79, 135-137, 147, 149; Lehm, 1999, 28, 31.

47 Por entonces, a nivel nacional se sancionó el Decreto de 18 de enero de 1858 que debía proteger a la población indígena de los abusos de los que podían ser víctimas por parte de las autoridades, a la espera de que adquirieran «los atributos de la ciudadanía». Irurozqui, 2000, 62.

48 Las parcialidades perderían su función de agrupar a la población en función de su ocupación y, con el tiempo, serían sustituidas las manzanas donde se vivía, en Van Valen, 2003, 29-32; 2011, 624-628.

49 Limpias Saucedo, 2005 [1942], 132-136

50 Ibidem, 134.

51 Block, 1997, 144-154. 
sería ahora la máxima autoridad indígena y mantendría el cargo mientras desempeñara correctamente sus funciones. Supeditados a él estaban los intendentes, los capitanes de parcialidades, los tenientes, los alcaldes, los comisarios, los fiscales y los alguaciles. Para rodearlos del respeto que merecían, se dispuso, años después, que la toma de posesión del cargo por parte de los cabildantes conllevaría un acto oficial para visualizar la importancia de las funciones del cabildo..$^{52}$ Este poseía dos dimensiones: una interna y otra externa. De un lado, la ceremonia suponía una sanción comunal de las jerarquías de autoridad. De otro, el hecho de que fuese la prefectura la que, formal y solemnemente, sancionara el poder y las responsabilidades del cabildo y los cargos a él sujetos, implicaba no solo el reconocimiento estatal hacia las autoridades y representantes nativos, sino también su integración en el organigrama institucional exterior. ${ }^{53}$

La nueva organización del espacio beniano comportó que el cargo de corregidor pasara no sólo a ser ejercido por un empleado público designado por la prefectura, sino que recayera, generalmente, en un individuo de extracción criolla-mestiza. Como ya dijimos antes, por ahora conocemos solo el caso de un indígena, Frutos Nosa, que ejerció tal cargo en Trinidad entre 1843 y 1845, año en que renunció para tomarlo de nuevo desde 1849 hasta iniciada la década de $1860 .{ }^{54}$ Durante este último periodo, mientras Nosa actuaba de corregidor, Mariano Cayuba lo hacía de cacique. Un viajero estadounidense, refiriéndose a ambos individuos, señaló que «Cayuba era el hombre sabio de la tribu de los mojos. Era respetado por su inteligencia, mientras que Fratos [sic] mantenía un rango mayor debido a su riqueza. Cayuba pensaba que eso era injusto; mientras que él realizaba su trabajo bien y su casa era la más llamativa del pueblo, el hombre más importante cerca de él le recordaba constantemente que él debía ser nombrado corregidor». ${ }^{55} \mathrm{~A}$ la luz de estas palabras el cabildo reorganizado mantuvo la dimensión jerárquica de la sociedad nativa a lo largo del siglo XIX. Pero si durante el régimen misional la dirección del gobierno comunal había recaído en aquellos jefes que tenían autoridad moral sobre el pueblo común, a medida que la reforma de Ballivián se asentaba, las autoridades tradicionales vieron reacomodado su poder en beneficio de criterios de peso eco-

52 Limpias Saucedo, 2005 [1942], 134-136, 148.

53 Alda Mejías, 1999, 246.

54 ABNB, MI, Prefectura del Beni, 96/48, 10 de octubre de 1843; 107/33, 30 de septiembre de 1845,$120 ; 134 / 36,13$ de febrero de $1850 ; 155 / 38,5$ de julio de 1855 .

55 Gibbon, 1993 [1852], 307, 309. 
nómico. El lamento de Cayuba respecto a que Frutos Nosa formaba parte de los indios principales, era letrado y poseía suficientes bienes, expresaba no solo el cambio que se estaba operando en el seno de la comunidad nativa, sino también permite constatar que junto a la división funcional entre pueblo y familia, existían otras diferencias entre sus miembros relativas a los privilegios que estos podían gozar en virtud de valores acordes con los principios de riqueza y progreso nacionales. ${ }^{56}$

El cabildo formalizó el ejercicio de autoridad en el seno de la sociedad nativa con la creación de cargos, roles y funciones que debían realizarse a favor del orden público. El cacique quedó sujeto al corregidor, del que recibía y acataba órdenes relativas a la organización de los trabajos comunitarios y la conservación de la moral cristiana, con lo que la autoridad del corregidor desplazó a los cabildantes de sus funciones de mediación, provocando la cooptación y el desplazamiento de sus estructuras de decisión. ${ }^{57}$ Ello les situó en una posición incómoda. Se sabe que los corregidores abusaban con frecuencia de su $\operatorname{cargo}^{58}$ y en sus exigencias involucraron a los cabildantes. Si bien éstos eran los que debían señalar qué indígenas debían trabajar en las obras de carácter público, también intervenían en la contratación particular respecto a trabajos diversos como la navegación de los ríos, el corte de quina o la extracción de la goma elástica. ${ }^{59}$ Estos cambios no impidieron al cabildo jugar un papel activo y destacado en la defensa de la sociedad indígena. Considerado el representante legítimo de la misma, su autoridad fue reconocida por los empleados públicos criollo-mestizos y, hasta fines del siglo XIX, fue requerido para dilucidar conflictos de distinta índole, siendo considerada su palabra elemento suficiente de legitimidad. Como observaremos en el próximo acápite, desde 1842 uno de los derechos civiles más queridos por los indígenas fue el acceso a la propiedad de la tierra. En este sentido, a lo largo del siglo XIX el cabildo indígena fue exhor-

56 Junto a Frutos Nosa, otros personajes significativos fueron José Gregorio Acuruza, quien durante años ejerció de cacique en Exaltación y fue propietario de establecimientos donde trabajaban hombres, mujeres y niños que ejercían de tejedores, remeros, criaban el ganado y cultivaban sus chacos; e Hipólito Ojopi, cacique de Baures, cuyo matrimonio con una cruceña redundó su autoridad tradicional sociopolítica entre los nativos con su nuevo estatus económico. Coimbra, 1993, 51-52; Van Valen, 2003, 88-89.

57 Cortés, 1989, 42-43; Block, 1997, 235-236.

58 ABNB, MI, Prefectura del Beni, 96/48, 22 de julio de 1843 y 10 de octubre de 1843; 143/25, 27 de mayo de 1852; 216/49, 16 de diciembre de 1883; 218/42, 27 de noviembre de 1884; 228/59, 1 de junio de 1886; 244/61, 23 de diciembre de 1889.

59 Ver ABNB, Ministerio de Hacienda, Siglo XIX-Prefectura del Beni, 141/28, 1 de julio de 1855 y ACCB, Denuncia al cacique de Trinidad, 10 de enero de 1868. 
tado por la prefectura y la municipalidad a informar sobre la pertinencia de las solicitudes de tierras, especificando quiénes las ocupaban, denunciando la usurpación de las mismas, si era el caso, y amparando, mediante la legislación vigente, los derechos de posesión de los nativos. Ello permite afirmar que, pese a los cambios institucionales operados, las funciones originarias del cabildo indígena sobrevivieron a lo largo del siglo XIX.

\section{Los indígenas benianos y su acceso a la propiedad de la tierra}

El Decreto de 6 de agosto de 1842 estipulaba la extensión de una ciudadanía de corte censitario a toda la población nativa, permitiendo ello que miembros de la misma aprovechasen los recursos ofrecidos por la legislación para ejercer el derecho de propiedad. Gracias a ello, adquirieron «pleno dominio» de los terrenos que ocupaban y por los que debían efectuar el pago de una contribución anual. En este sentido, la ciudadanía que les fue otorgada estaba íntimamente vinculada a su estatus fiscal, manteniendo a los indígenas como un colectivo diferenciado a cambio de la posesión de la tierra y convirtiendo la tasa señalada en el elemento que certificaba su acceso a la propiedad y probaba su desempeño ciudadano. ${ }^{60}$ En otras palabras, los nativos benianos adquirieron el estatus de tales por su condición de tributarios y poseedores de tierras. Aunque a lo largo del siglo XIX este estatus iría desdibujándose, las disposiciones de 1842 permitieron que un número relevante de esta población se hiciera un hueco en la nueva sociedad republicana a través del trabajo y de la propiedad de la tierra.

Los títulos expedidos según las disposiciones de 1842 amparaban la ocupación y el trabajo de los indígenas, pero solo acreditaban su calidad de «usufructuarios». Por este motivo, hasta inicios del siglo XX, muchos indígenas mostraron la voluntad de adquirir una escritura pública que les otorgara la propiedad definitiva sobre la tierra que trabajaban, reconociéndose como una «porción de bolivianos [...] quienes para elevarse a la clase de ciudadanos necesitan ser propietarios» ${ }^{61}$ Una primera oleada de solicitudes de títulos de propiedad tuvo lugar en la década de 1840 con la creación del departamento y se apoyaron en el Decreto de 6 de agosto. Los lotes solicitados eran los más aptos para el pastoreo y, en menor medida, para el

60 Demélas, 2002 [1992], 63; Irurozqui, 2006, 35-66.

61 ABNB, Instituto Nacional de Colonización (en adelante IC), 763.33, solicitud de Frutos Nosa, 1849. 
cultivo; esto se entiende porque la extensión de los primeros era mucho mayor que la de los segundos. En este sentido, los motivos esgrimidos para adquirir los títulos de propiedad legal de los terrenos repartidos en virtud de los decretos de 1842 aludían a la voluntad de asegurarse un lugar que facilitara la supervivencia familiar y que pudiese transmitirse a los herederos. ${ }^{62}$ Las solicitudes fueron tramitadas, en su gran mayoría, por individuos con medios para sufragar los gastos de la compra y que al hacerlo realzaban su rango social y sus capacidades letradas y pecuniarias alegando los cargos que ejercían en la comunidad y autodesignándose como ciudadanos. ${ }^{63}$ Un segundo momento de compra de tierras tuvo lugar a partir de $1860 \mathrm{y}$, de nuevo, sus solicitantes se apoyaron en lo decretado en 1842 respecto a la protección «a los antiguos pobladores», haciendo de «la natural oriunda» «casta» indígena «dueñ[a] absolut[a]» de la tierra. ${ }^{64} \mathrm{~A}$ diferencia del periodo anterior, los predios más demandados fueron los de cultivo y la mayoría de las solicitudes fueron presentadas por indígenas del común que argumentaron en defensa de su petición el haber prestado servicios a la comunidad; siendo pocos los que alegaron su actuación sociopolítica. También aludían a la pérdida y/o falta de los títulos y a su voluntad por legalizar su posesión de la tierra; ${ }^{65}$ y mientras seguían enfatizando la voluntad de asegurarse un espacio que permitiera sostener a sus familias, la mayoría manifestó la necesidad de frenar la presión de los colonos criollo-mestizos. ${ }^{66}$ Tal demanda mostraba que su expansión afecta-

62 ABNB, IC, 827.7, solicitud de Lucas Maleca, 1849; 819.15, solicitud de Luís Achaco, 1843; 831.33, solicitud de Andrés Erechi, 1842; 826.3, solicitud de Pablo Gualasúa, 1842; 763.33, solicitud de Frutos Nosa, 1849.

63 Ver ABNB, IC 827.7, solicitud de Lucas Maleca, 1849; 820.11, solicitud José B. Zárate, 1849; 827.14, solicitud de Pablo Camino, 1842; 763.33, solicitud de Frutos Nosa, 1849; ACCB, Registro de Escrituras, solicitud de Mariano Necopuyero, 1875.

64 ACCB, Registro de Escrituras, solicitud de Amalia Cortés, 1867; solicitud de Pedro Jocoroho, 1867; solicitud de Pedro Taborga, 1872; solicitud de Manuel de la Cruz Mobo, 1873; solicitud de José Gregorio Acuruza, 1873; solicitud de Mariano Noe, 1874.

65 ACCB, Registro de Escrituras, Manuel Mariano Nosa Cueva, 1865; solicitud de Manuel María, Gregoria y Dolores Maebo, 1868; solicitud José María Nacuitiro, 1868; solicitud de Hilarión Ojopi, 1867; solicitud de María Cruz Acuruza, 1867; solicitud de Bernabé Pinaicobo, 1867; solicitud de Prudencio Nosa, 1870; solicitud de Manuel Prudencio Semo, 1870; solicitud de Juan y Antonio Yoyo, 1872; solicitud de Antonio Yubanure, 1873; solicitud de Bernardo Amabeja, 1873; solicitud de Felipa Zárate, 1875.

66 ACCB, Registro de Escrituras, solicitud de José Muiba, 1867; solicitud de Ignacio Nosa, 1867; solicitud de Bartolomé Teco, 1868; solicitud de José María Nacuitiro, 1868; solicitud de María Rosario Nabono, 1868; solicitud de José Egidio Yoqui, 1872; solicitud de Juan y Antonio Yuyo, 1872; solicitud de Ignacio Guaji, 1873; solicitud de comunarios, 1873; solicitud de José Felipe Nosa, 1874; solicitud de Mariano Noe, 1874. 
ba a toda la población nativa, con independencia de su lugar en la jerarquía comunitaria, y daba cuenta del claro interés de los nativos por evitar ésta y la sobreexplotación de los recursos naturales a través del ejercicio de la ley. Así, los indígenas del común fueron incorporando mecanismos que los aproximaron al ejercicio ciudadano, quizá primero no por voluntad pero sí por la necesidad. ${ }^{67}$ Buen ejemplo de ello fue una solicitud presentada por el cabildo indígena de Trinidad en 1880, donde se afirmaba que «desde sus antepasados hasta el presente vienen ejerciéndolo [su posesión de la tierra] con variados cultivos, de que únicamente como subsisten haciendo uso de la leña y maderamen que dan los bosques, en beneficio propio y del público [...] aprovech[ándolo] en común, para sus ganados de los bajíos o pastales [sic] [...]. [De estos terrenos] se les quiere despojar o se les ha despojado ya en mucha parte, porque no hay para ellos justicia ni protección de parte del mismo funcionario que solicita comprar el terreno, quien no se sabe como dicen se ha establecido con sus labranzas sobre la margen de [los ríos], privándoles de los caminos de los bosques». ${ }^{68}$

A inicios de la década de 1880 aún existía un acceso diferenciado a la tierra por parte de los nativos, distinguiendo los que poseían títulos de propiedad de quienes carecían de ellos. Asimismo, también había un elevado número de indígenas que, con o sin título, trabajaban individualmente la tierra, aunque la posesión comunal — de la que participaba la mayoría de la población - se mantuviese. ${ }^{69}$ La ausencia de escrituras públicas continuaba siendo la principal dificultad a superar. Con el objetivo de paliar esta situación se promulgó la Ley del 24 de noviembre de 1883. En ella se declaró «a los indígenas benianos propietarios absolutos» de las tierras que ocuparan o poseyeran, y se decretó el acceso gratuito a la propiedad de la tierra. ${ }^{70}$ Esta ley vino a corroborar lo sancionado en 1842, respecto a que todo aquél que quisiera legitimar sus derechos de ocupación podía hacerlo obteniendo la escritura pública correspondiente. De ahí que, a partir de entonces, se diese una tercera oleada de solicitudes de títulos de propiedad. Ahora, se podría acceder gratuitamente a la propiedad de terrenos ocupados efectivamente; motivo por el que en las peticiones, los indígenas decían ocupar esos lotes desde hacía años y sin interrupción, viviendo y trabajan-

67 En este sentido véase el trabajo de Quijada (2011, 149-307) relativo al proceso de configuración ciudadana entre los nativos de la frontera patagónica a lo largo del siglo XIX.

68 ABNB, IC 850.21, solicitud del cabildo indígena, 1880.

69 Ver los catastros de predios rústicos de los pueblos de Trinidad, Santa Ana y Exaltación en ALP, SGL, 1881, 3/62, 2 de abril de 1881 y 3/63, 20 de abril de 1881 y 2 de noviembre de 1881.

70 República de Bolivia, 1884, 285-286. 
do en ellos con cultivos diversos. Como en muchos casos manifestaban que habían extraviado sus antiguos títulos pese a habérseles repartido los lotes ${ }^{71}$ resultaba notoria la preocupación general por no tener con qué «acreditar en todo tiempo y forma el derecho de propiedad» sobre los terrenos que ocupaban, escrituras que "asegur[aría]n nuestros derechos». ${ }^{72}$ El resultado de este tercer proceso fue la drástica disminución de la propiedad comunal a favor de una propiedad individual y el crecimiento de la demanda de lotes aptos para el pastoreo y las actividades agropecuarias. Este último factor respondía al interés por acceder gratuitamente a una mayor superficie de terreno, ya que los lotes para pasto siempre fueron mayores que los de cultivo, y a la necesidad de salvaguardar los recursos naturales de la presión de los colonos. Ocurría así debido a que la ley también preveía la adquisición de terrenos previo pago de cien bolivianos; lo que podía comportar la ocupación sistemática de los mejores terrenos por parte de los que pudieran asumirlo: indígenas con medios económicos y los grupos criollo-mestizos.

En suma, los decretos de 1842 y los que posteriormente los corroboraron posibilitaron que la población indígena viera asegurado su acceso a la propiedad de la tierra y, con ello, favorecido su desempeño como sujetos productivos, luego ciudadanos. La gran cantidad de solicitudes de tierras tramitadas hasta fines del siglo XIX probaban que desde un primer momento hubo un claro interés por parte de la sociedad nativa por construir el espacio regional y participar de la vida departamental mediante el recurso a las leyes y el uso de los mecanismos jurídicos establecidos por la administración pública.

\section{Epílogo}

Las posibilidades de participación de los nativos en la sociedad republicana y, por ende, en la construcción del departamento disminuyeron progresivamente a partir de la década de 1890 . Por entonces aumentó la pre-

71 ACCB, Registro de Escrituras, solicitud de Martías Notu, 1885; solicitud de Lorenzo López y Carmen Mercado, 1885; solicitud de Juan Antonio Mesúa, 1885; solicitud de Vicente Malale, 1885; solicitud de Manuel Vicitación Noe, 1885; solicitud de comunarios, 1886; solicitud de Manuel de la Cruz Teco, 1887; solicitud de Prudencio Nosa, 1894; solicitud de Mateo Nosa, 1894; solicitud de Petrona Yubanure, 1894; solicitud de Sebastián Ichu, 1894.

72 ACCB, Registro de Escrituras, solicitud de Lorenzo Cortés y Rosario Taborga, 1885; solicitud de Manuel Vicitación Noe, 1885; solicitud de José Egidio Yoqui, 1887. 
sencia criollo-mestiza en las diversas instancias de poder como consecuencia, primero, de la mayor complejidad adquirida por la organización político-administrativa departamental; ${ }^{73} \mathrm{y}$, segundo, por el desarrollo de la explotación de goma elástica en el norte amazónico y las políticas de colonización planteadas por el gobierno central. ${ }^{74} \mathrm{Si}$ los decretos e instrucciones de 1842 ya preveían en sus distintos artículos la llegada de población criollo-mestiza a la región, y la ley de 1883 atraía a nuevos pobladores por otorgarles tierras previo pago de cien bolivianos, las posteriores disposiciones de «tierras baldías» fomentaron claramente la colonización del área al tiempo que limitaron la propiedad indígena. La Ley de 13 de noviembre de $1886^{75}$ contribuyó a colonizar el departamento, por un lado, ofreciendo facilidades a los que quisieran desplazarse a la región y expandir la economía agropecuaria y, por otro lado, manteniendo el acceso gratuito a lotes de tierra dedicados a actividades agrícolas, cuya superficie se redujo de forma exponencial respecto a las disposiciones anteriores. A ello se agregó la Ley de 26 de octubre de $1905^{76}$ que supuso un cambio cualitativo sobre la cuestión al convertirse en el único elemento normativo acerca del acceso a la propiedad de la tierra. Esta ley, además de favorecer la colonización, estableció el pago de diez centavos por hectárea para obtener lotes de cultivo y/o pastoreo de propiedad. Ello supuso el asalto definitivo a la tierra por parte de los grupos económicos criollo-mestizos que, paulatinamente, se harían con grandes extensiones de terreno, convirtiéndose en los grandes latifundistas de la región. Desde fines de la década de 1880 los indígenas vieron cómo sus tierras eran ambicionadas por los nuevos colonizadores que presionaban sobre sus posesiones e incluso llegaban a establecerse por la fuerza en tierras que ya tenían legítimos propietarios. Si bien en algunos casos los títulos de propiedad adquiridos permitieron expulsar a estos colonos, en la mayoría de situaciones, la presión ejercida fue tan significativa que los nativos cedieron finalmente, vendiendo sus casas y lotes de terreno. ${ }^{77}$ En medio de este proceso, unas pocas familias indígenas mantuvieron, e incluso, aumentaron sus propiedades, formando así parte de los grupos de poder locales y regionales, cuyo estatus estaba

73 Guiteras Mombiola, 2011a, 80-84, 92-100.

74 García Jordán, 2001; Gamarra, 2007.

75 La ley puede revisarse en http://www.lexivox.org/norms/BO-L-18861113-1.html (consultada el 18 de mayo de 2012).

76 La ley puede revisarse en Ballivián y Pinilla, 1912, XLVII-LII.

77 Lehm, 1987. 
más vinculado a la lógica de poder socioeconómico que a la de la autoridad tradicional legada por los jesuitas.

Resultado también del auge gomero y de la incorporación al mercado laboral del norte amazónico de gran cantidad de indígenas fue la mengua de la importancia de las autoridades indígenas. El papel que a lo largo del siglo XIX había jugado el cabildo empezó a declinar, ya que desde distintos ámbitos se promovía una mayor supeditación de los cabildantes a las entidades organizadas desde el gobierno e integradas por población criollomestiza; llegando algún miembro destacado de la sociedad beniana a solicitar la eliminación del cabildo. ${ }^{78}$ A pesar de que eso no ocurrió, a partir de la década de 1890 esta institución dejó de ser requerida para dilucidar el estado de ocupación de los lotes solicitados, perdiendo el poder y la legitimidad de la que había gozado entre las autoridades públicas hasta entonces. Ese alejamiento de los nativos de las esferas de poder y decisión locales y regionales se hizo evidente en la desaparición de las listas electorales de sufragantes con apellidos indígenas. Un ejemplo de su progresivo descrédito ciudadano se advirtió durante la elección de munícipes en Magdalena en 1886. A causa de un conflicto de abuso de poder por parte del presidente municipal, su colegas afirmaron que éste «ha pretendido siempre y esforzándose hasta el extremo en que los miembros del cuerpo municipal de esta provincia se componga de indígenas para de este modo hacerse su voluntad [y] sea [ésta] la que impere en el ánimo de los municipales $[\ldots]$ y los pobres indios, sus colegas, ignorantes de todo ni siquiera del contenido de los oficios que él dirige como Presidente en nombre de ellos». ${ }^{79} \mathrm{Si}$ bien la acusación de malas prácticas fue avalada por el gobierno ${ }^{80}$ la cita daba cuenta del cambio que se estaba gestando en el seno de la sociedad boliviana. Al iniciarse el siglo XX, el cabildo indígena había perdido su relevancia política, la élite nativa era alejada de las municipalidades, relegándose su autoridad al ámbito del cabildo, y la superficie de terreno a la que podían acceder gratuitamente era cada vez más reducida.

Con todo, en nuestra opinión, el proceso descrito a lo largo de la segunda mitad del siglo XIX no invalida la tesis según la cual el recuerdo, el conocimiento y los usos nativos de la legislación aprobada en 1842 favorecieron la conciliación de sus garantías constitucionales con el desarrollo

78 Ver Salvatierra, 1872, 7-9.

79 ABNB, MI, Prefectura del Beni, 228/59, 2 de enero de 1886. de 1886.

80 ABNB, MI, Prefectura del Beni, 228/59, 13 de diciembre de 1885 y 2 de enero-12 de abril 
departamental. Lejos de permanecer en una actitud pasiva, diversos miembros de la sociedad indígena elaboraron distintas estrategias para defender su acceso a las tierras, desarrollaron actividades agropecuarias que al generar riqueza regional legitimaban su peso público y social y actuaron en instituciones políticas locales y departamentales como ciudadanos bolivianos, siendo fundamental en este proceso la actividad del cabildo.

Recibido el 01 de septiembre de 2012 Aceptado el 16 de octubre de 2012

\section{Fuentes y Bibliografía citadas}

Aguirre, Joaquín de: Memoria que el Ministro del Interior y del Culto presenta al Congreso Extraordinario de 1855, Sucre, s.p.i., 1855.

Alda Mejías, Sonia: La participación indígena en la construcción de la república de Guatemala, s. XIX, Madrid, Universidad Autónoma de Madrid, 1999.

Ballivián, Manuel Vicente y Pinilla, Casco: Monografía de la industria de la goma elástica en Bolivia, La Paz, Dirección General de Estadística y Estudios Geográficos, 1912.

Barragán, Rossana: Indios, mujeres y ciudadanos. Legislación y ejercicio de la ciudadanía en Bolivia (Siglo XIX), La Paz, Fundación Diálogo-Embajada del Reino de Dinamarca en Bolivia, 1999.

Bourdieu, Pierre: Ce que parler veut dire: L'économies des échanges linguistiques, Paris, Fayard, 1982.

Block, David: La cultura reduccional en los Llanos de Mojos, Sucre, Historia Boliviana, 1997.

Coimbra, Juan B.: Siringa. La Paz, Librería Editorial América SRL, 1993 [1946].

Cortés, Jorge: «Notas al diario del P. Gumercindo Gómez de Arteche», en JHS Misión de los PP Astraían, Mansanedo y Arteche c. a. 1888, Trinidad, CIDDEBENI: Documentos Históricos, 1989, 34-44.

Dalence, José María: Bosquejo estadístico de Bolivia, Chuquisaca, Imprenta de Sucre, 1851.

Demélas, Marie Danielle: La invención política. Bolivia, Ecuador, Perú, siglo XIX, Lima, IEP/IFEA, 2002 [1992].

Escobar O., Antonio (coord.): Los pueblos indios en los tiempos de Benito Juárez, México, Universidad Autónoma «Benito Juárez» de Oaxaca-Universidad Autónoma Metropolitana, 2007.

Echeverri, Marcela: «Los derechos de indios y esclavos realistas y la transformación política en Popayán, Nueva Granada (1808-1820)», Revista de Indias, LXIX-246, Madrid, 2009, 45-72. 
«LOS NATURALES SON CIUDADANOS DE LA GRAN FAMILIA BOLIVIANA»

Galante, Mirian, Irurozqui, Marta, y Argeri, María: La razón de la fuerza y el fomento del derecho. Conflictos jurisdiccionales,ciudadanía y mediación estatal (Tlaxcala, Bolivia, Norpatagonia, siglo XIX), Madrid, CSIC, 2011.

Gamarra, María del Pilar: Amazonia Norte de Bolivia. Economía Gomera, 18701940. Bases económicas de un poder regional: La Casa Suárez. La Paz, Colegio Nacional de Historiadores de Bolivia-Producciones CIMA Editores, 2007.

Gamarra, María del Pilar: «El desarrollo del concepto Beni. Proceso socio-histórico de formulación de la idea de Beni en la memoria colectiva de sus comunidades sociales», en Suárez, Justa (coord.): Cultura e Identidad beniana, Trinidad, Prefectura del Beni/PIEB/PNUD/ACDI, 2010, 15-37.

García Jordán, Pilar: Cruz y arado, fusiles y discursos. La construcción de los Orientes en el Perú y Bolivia, 1820-1940, Lima, IFEA-IEP, 2001.

Gibbon, Lardner: Exploración del Valle del Amazonas, II, Iquitos, CETA/AbyaYala/ CCOP, 1993 [1852].

Groff Greever, Janet: José Ballivián y el Oriente Boliviano, La Paz, Editora Siglo Ltda., 1987.

Guiteras Mombiola, Anna: Para una historia del Beni. Un estudio socioeconómico, político e ideológico de la amazonía boliviana, siglos XIX-XX, Tesis de Doctorado, Universidad de Barcelona, 2011a.

Guiteras Mombiola, Anna: «La mano de obra indígena en el comercio fluvial del Beni (Bolivia) en la segunda mitad del siglo XI», Bulletin de l'Institut Français d'Études Andines, 40-3, Lima, 2011b, 511-532.

Irurozqui, Marta: A bala, piedra y palo. La construcción de la ciudadanía política en Bolivia, 1826-1952, Sevilla, Diputación de Sevilla, 2000.

Irurozqui, Marta: La ciudadanía en debate en América Latina. Discusiones historiográficas y una propuesta teórica sobre el valor público de la infracción electoral, Lima, IEP, 2005a.

Irurozqui, Marta: «De cómo el vecino hizo al ciudadano en Charcas y de cómo el ciudadano conservó al vecino en Bolivia, 1808-1830», en Rodríguez, Jaime E., (ed.): Revoluciones, Independencia y las nuevas naciones de América, Madrid, Fundación Maphre-Tavera, 2005b, 451-484.

Irurozqui, Marta: «Sobre el tributo y otros atributos ciudadanos. Sufragio censitario, fiscalidad y comunidades indígenas en Bolivia, 1825-1839», Bicentenario. Revista de Historia y de Ciencias Sociales, 6, Santiago de Chile, 2006, 35-66.

Irurozqui, Marta: «El espejismo de la exclusión. Reflexiones conceptuales acerca de la ciudadanía y el sufragio censitario a partir del caso boliviano», Ayer, 70-72, Madrid, 2008, 57-92.

Irurozqui, Marta y Galante, Mirian (eds.): Sangre de Ley. Violencia y justicia en la institucionalización del Estado. América Latina, siglo XIX, Madrid, Ed. Polifemo-GEA, 2011. 
Lehm, Zulema: «Diagnóstico de la situación actual de los indígenas de Trinidad y áreas cercanas», en Simposio sobre las Misiones jesuitas en Bolivia, La Paz, Ministerio de Relaciones Exteriores y Culto, 1987, 205-213.

Lehm, Zulema: La búsqueda de la Loma Santa y la Marcha Indígena por el Territorio y la Dignidad, Santa Cruz de la Sierra, APCOB-CIDDEBENIOXFAM América, 1999.

Limpias Saucedo, Manuel: Los Gobernadores de Mojos, Trinidad, Prefectura del Beni, 2005 [1942].

Méndez, Cecilia: The Plebeian Republic. The Huanta Rebellion and the Making of the Peruvian State, 1820-1850, Durham y Londres, Duke University Press, 2005.

Moreno, Gabriel-René: Colección de documentos bolivianos recogidos y ordenados por [...], I, 40. Santiago de Chile, s.p.i., 1872.

Oficina Nacional de Inmigración, Estadística y Propaganda Geográfica: Censo general de la población de la República de Bolivia, II, La Paz, Taller TipoLitográfico de J. M. Gamarra, 1904.

Orbigny, Alcides d': Descripción Geográfica, Histórica y Estadística de Bolivia, París, Librería de los Señores Gide y Compañía, 1846.

Orbigny, Alcides d': Viaje a la América Meridional, IV, Buenos Aires, Editorial, Futuro, 1945 [1835-1847].

Quevedo, Quintín: Pequeño bosquejo de la provincia de mojos en el departamento del Beni, La Paz, Imprenta Paceña, 1861.

Quijada, Mónica: «El paradigma de la homogeneidad», en Quijada, M., Bernand, C. y Schneider, A.: Homogeneidad y nación con un estudio de caso: Argentina siglos XIX y XX, Madrid, CSIC, 2000, 15-55.

Quijada, Mónica: «La caja de Pandora. El sujeto político indígena en la construcción del orden liberal», Historia Contemporánea, 33-II, Vizcaya, 2006, 605637.

Quijada, Mónica: «La lenta configuración de una "ciudadanía cívica” de frontera. Los indios amigos de Buenos Aires, 1820-1879 (con un estudio comparativo Estados Unidos-Argentina)», Quijada, Mónica (ed.): De los cacicazgos a la ciudadanía. Sistemas políticos en la frontera, Río de la Plata, siglos XVIIIXX, Berlín, Iberoamericana, 2011, 149-307.

República de Bolivia: Anuario de Leyes y Supremas Disposiciones de 1883, La Paz, Imprenta de El Comercio, 1884.

Roca, José Luís: Economía y Sociedad en el Oriente Boliviano (siglos XVI-XX), Santa Cruz, COTAS Ltd, 2001.

Rodríguez O., Jaime E.: «Ciudadanos de la nación española: los indígenas y las elecciones constitucionales en el reino de Quito», en Irurozqui, Marta (ed.), La mirada esquiva. Reflexiones históricas sobre la interacción del Estado y la ciudadanía en los Andes (Bolivia, Ecuador y Perú), siglo XIX, Madrid, CSIC, 2005, 41-64. 
Salvatierra, Juan de Dios: Documentos que comprueban la conducta nada honrosa de D. Ramón Barberi, prefecto del Departamento del Beni, Santa Cruz, Imprenta de Cayetano R. Daza, 1872.

Van Valen, Gary: The Ventriloquist Messiah and his Followers: Mojo Indian Responses to the Rubber Boom in Eastern Bolivia, 1860-1930, Ph.D. diss., University of New Mexico, 2003.

Van Valen, Gary: «De Mojos a Beni: los indígenas y la reforma gubernativa en la Amazonía boliviana, 1842-1860», Anuario de Estudios Bolivianos, Archivísticos y Bibliográficos, 17, Sucre, 2011, 599-634. 